\title{
Lecture One: Rediscovering Darwin for theology - Rethinking human personhood
}

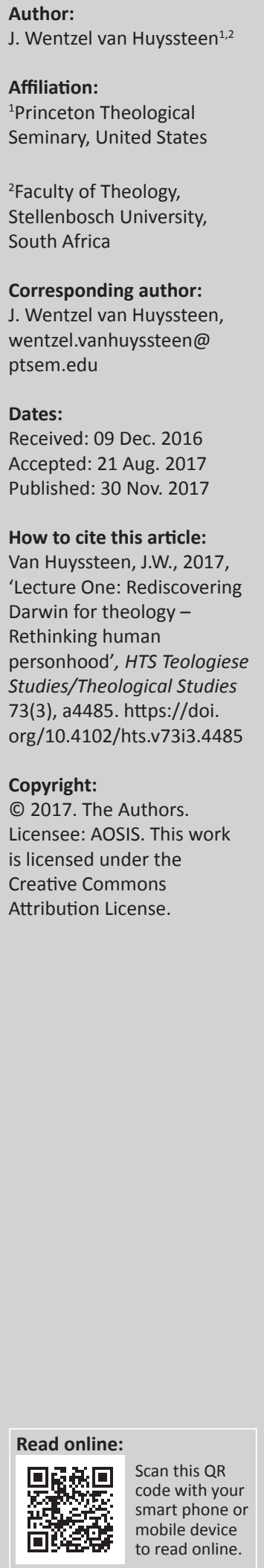

In a series of three articles, presented at the Goshen Annual Conference on Science and Religion in 2015, with the theme 'Interdisciplinary Theology and the Archeology of Personhood', J. Wentzel van Huyssteen considers the problem of human evolution - also referred to as 'the archaeology of personhood' - and its broader impact on theological anthropology. These Goshen Lectures explore the potentiality that the history of human evolution provides bridge theories to theological anthropology and thus to a positive and constructive way of appropriating Darwinian thought for a public, interdisciplinary Christian theology. Lecture One tracks a select number of contemporary proposals for the evolution of aspects of human personhood. These aspects were of significance for Darwin: the evolution of cognition; the evolution of imagination, music and language; the evolution of morality; and the evolution of the religious disposition. The article acknowledges the close ties to hominid ancestors and focuses on the emergence of human distinctiveness, consciousness and personhood, and the propensity for religious awareness and experience.

\section{Introduction}

All three of my Goshen Lectures represent core perspectives on one of the most salient shared problems today in the interdisciplinary dialogue between theology and the sciences, the problem of human personhood. I want to ask whether the history of human evolution as such might provide us with important bridge theories to theological anthropology and thus to a positive and constructive way of appropriating Darwinian thought for a public, interdisciplinary Christian theology. From a more philosophical point of view, I am asking whether Darwin's perspective on human evolution can help us move forward to more constructive, holistic notions of self and personhood, and thus to make more intelligible what anthropologist Chris Fowler had called 'the production of personhood' (cf. Fowler 2004). I will presuppose in these lectures what I have argued elsewhere, which is that in the history of hominid evolution we find surprising answers to the enduring question of what it means to be a self, a human person(van Huyssteen 2006; 2009; 2010a; 2010b; 2010c; 2011; 2013). In fact, what we now know about key aspects of hominid/ hominin evolution affirms what Darwin argued for as crucial aspects of human distinctiveness, or human species specificity. To this end I want to consider the problem of human evolution or 'the archaeology of personhood' (cf. Fowler 2004) and its broader impact on theological anthropology, by tracking a select number of challenging contemporary proposals for the evolution of crucially important aspects of human personhood, aspects that were all of great significance for Darwin: the evolution of cognition; the evolution of imagination, music and language; the evolution of morality; and the evolution of the religious disposition. In this way, I hope to show that the evolution of these crucial aspects of humanness ultimately converge on the complex problem of the evolution of human nature and of the human self.

\section{Rethinking Darwin on human evolution}

Today then, and not surprisingly, scholars from numerous and highly diverse fields are not only addressing the question of what makes us human and what it means to be a 'self' but are also seeking multidisciplinary input from other disciplines to inform and enhance their answers to this fundamental issue. These questions do not only pertain to empirical questions about what distinguishes humans from their hominid ancestors, but they often also refer to a very different kind of question, namely, which of our specific peculiarities gives us humans our distinctive 'species specificity' and significance? What is interesting is that this question is specifically not only empirical, because we humans in a sense actually draw the hominin-human boundary in ways that are also determined by our cultural contexts (cf. Cartmill \& Brown 2012:182). 
One popular way of defining human distinctiveness is, of course, to make a clear distinction between anatomical and behavioural differences ${ }^{1}$.

The meaning, the markers and the justification of human identity and status have of course fluctuated throughout Western academic history. Generally, of course, language has been viewed as a crucial marker (cf. Deacon 1997; Mellars 1989; 1991; Mithen 1996; Nobel \& Davidson 1996; Tattersall 1998, 2002). In addition, conceptions of defining humanness have lately shifted towards our capacity for 'prosociality,' which we share with primates, as well as our unique propensity for imitation (cf. Cartmill \& Brown 2012:182). Also, music (Mithen 2006), sexuality (Sheets-Johnstone 1990) and empathy (Boehm 2012; de Waal 2006, 2013; Kirkpatrick 2005; Sheets-Johnstone 2008) are in the process of being thoroughly researched and hailed as the foundation not only of language, social norms and morality but also of symbolic and even religious behaviour.

The other genuinely panhuman trait is the remarkable human capacity for seeing things from someone else's perspective, generally known as Theory of Mind. Humans are indeed strongly disposed to intuitively understanding the motivations of others - so much so that we often see motivations where they do not exist (cf. Cartmill \& Brown 2012:182). This unique ability does, however, give us adaptively valuable insights into the intentions of our friends, enemies, predators and prey. And, as is well known, both sadism and compassion are neurologically grounded in this disposition (cf. Cartmill \& Brown 2012:182).

For scientists like Fuentes (cf. 2009) and Potts (cf. 1996; 2012), the real success of humans as a species can be attributed largely to our tendency and capacity for extreme alteration of the world around us. We not only construct material items, we also engage in the creation and navigation of social and symbolic structures, space and place, in a manner unequalled by other organisms. Most anthropologists would agree that human identity should be seen as interactively constructed by, and involved in the construction of, a conflux of biological, behavioural, social and symbolic contexts (cf. Fuentes 2009:12). The problem is that even anthropologists (like many theologians) often refuse to acknowledge a significant role for biological features and biological histories (evolution) in human action, sensation and engagement. According to the evolutionary anthropologist, Agustin Fuentes, anthropologists should counter this trend by

\footnotetext{
1.Cf. van Huyssteen (2006:203ff.): (1) Homo sapiens is the only surviving member of the family Hominidae, a group anatomically committed to terrestrial bipedalism. (2) Members of this species have (not uniquely) relatively large brains but with the most complex neocortex of all primates. (3) Their chinbearing faces are small compared with their neurocrania. (4) They have a brow region structured into two parts. In terms of a more behavioural definition, modern humans are identified by the unique presence of: (1) a spoken language (2) the cognitive capacity to generat mental symbols, as expressed in art and religion (3) explicit symbolic behaviour, that is, the ability to represent objects, people and abstract concepts with arbitrary symbols, vocal or visual, and to reify such symbols in cultural practices like painting symbols, vocal or visual, and to reify such symbols in cultural practices like painting, engraving, sculpture and music (cf. Lewis-Williams 2002:96f.) (4) the capacity for imaginative, abstract thinking, and the ability to act with reference to abstract concepts not limited to time and space (5) planning depth or the ability to formulat strategies based on past experience and to act upon that for the future, also in group context(6) behavioural, economic and technological innovation - to this can be added: (7) a bizarre inability to sustain prolonged bouts of boredom (cf. Tattersall \& Mowbray 2003:298)!
}

incorporating theoretical and research perspectives that do not just have interactive but also have creative, constructivist and evolutionary elements (cf. Fuentes 2009:12). For anthropology to become more familiar with 'post-neoDarwinian' evolutionary perspectives, this kind of mutual enrichment will certainly reveal a significant space for mutual enrichment and overlaps between anthropological and evolutionary approaches. I believe that the same would be startlingly true for interdisciplinary theology.

For this reason, and importantly, some evolutionary anthropologists actually now find the distinction 'Darwinian' and 'neo-Darwinian' unhelpful for many of the current evolutionary theories of interest, and argue that we should recognise that there is an expansive body of research and theory that is not captured by these headings anymore (cf. Fuentes 2009:12). Basic Darwinian theory prioritises natural selection and sexual selection as the prime factors in evolutionary change and the emergence of adaptations. Natural selection is generally seen as the process by which certain phenotypes (morphology and behaviour) that are most effective at reproducing themselves (and thus their genetic basis or genotype) in a given environment become more frequent in a population across generations. Sexual selection is the over-representation of specific phenotypes across generations as a result of mate choice and or intrasexual competition. Those traits that lead to the success of particular phenotypes and become the predominant traits in subsequent generations are termed adaptations. These traits, and the individual possessing them, are then said to be more 'fit'. And it is these 'fit' phenotypes that will strive for optimality and will rise to a majority status within the population over evolutionary time (cf. Fuentes 2009:12).

Without discounting the important role of natural and sexual selection in biological systems, some anthropologists want to emphasise that scientists are now expanding on Darwin's contributions, and invite us to focus on more recent, emerging trends in evolutionary theory. Evolutionary anthropologist Christopher Boehm, for instance, has recently pointed out how clearly Charles Darwin always implied that potentially changeable environments are continuously acting on the gene pool with significant results for evolutionary development and even speciation (cf. Boehm 2012:3f.). At the heart, then, of Darwin's project we already find what evolutionary biologists and anthropologists today are calling a process of niche construction: in a remarkable interactive process potentially changeable natural environments were acting continuously on variation in the gene pools of populations, and in this way gene pools were modified over generations.

It is especially interesting to note how most scholars today also acknowledge and accept a 'hierarchical progression' model of the evolution of symbolic and semiotic capabilities in humans (cf.; Mithen 1996; Noble \& Davidson 1996; Robinson 2010). Andrew Robinson (cf. Robinson 2010:1447) in particular has suggested that the three main assumptions behind these hierarchical approaches to human evolution and to human semiotic competence can be seen as follows: 
1. The evolution of human semiotic capability moves, in some sense, from the use of simple to more complex and sophisticated signs.

2. The culmination of this process is the capacity for using symbols (in the Peircean sense of signs related to their objects by convention).

3. Once this capability has been acquired, further developments in human evolution may follow from the possibility of using symbols in novel ways.

Implied in views like these is of course the fact that Darwinism is itself evolving. Andrew Robinson has focused in his work on the well-known 'three phases of evolution': the first major historical phase that stretched from the publication of the Origin of Species and lasted into the early 20th century; the second phase that culminated in the 'neo-Darwinian synthesis' and the combination of natural selection with Mendelian genetics; and the third phase that originated around the 1970s with various pressures on the neo-Darwinian synthesis, notably Gould and Eldridge's thesis for a 'punctuated equilibrium' that directly challenged conventional evolutionary gradualism (cf. Robinson 2010:182ff.). Robinson also helpfully suggests that these three phases in Darwinian evolution broadly correspond with three key themes in the history of evolutionary thinking: the theme of evolutionary continuity which arose particularly in the first phase of Darwinism, when the theory of 'descent with modification' became widely accepted in scientific circles; the theme of ontological naturalism which arose especially from the second phase of Darwinism, when the neoDarwinian synthesis demonstrated the power of natural selection as an evolutionary mechanism; and the theme of historical contingency, which has been much informed by new insights into complex system dynamics and the loosening of 'adaptationist' thinking in biology. ${ }^{2}$

It is, however, Eva Jablonka and Marion Lamb's important work, Evolution in Four Dimensions (2005), that calls for the renewal of evolutionary theory by arguing for 'evolution in four dimensions' rather than for a focus on just one, namely, the genetic. Jablonka and Lamb's basic claim is that biological thinking about heredity and evolution is undergoing a revolutionary change and what is emerging is a new synthesis that challenges the classic gene-centred view of new-Darwinism that has dominated biological thought for the last 50 years. In addition to genetics as an important inheritance system, Jablonka and Lamb now argue for three other inheritance systems that also have causal roles in evolutionary change. These other systems are the epigenetic, the behavioural and the symbolic inheritance systems. Epigenetic inheritance ${ }^{3}$ is found in all organisms, behavioural

2.Andrew Robinson moreover suggests that the relevance of evolutionary theory to theology might be developed precisely in terms of issues arising from the themes of continuity, naturalism and contingency (cf. 2010:1860).

3.On a cellular level, epigenetic differences are the consequences of events that occurred during the developmental history of each type of cell that determined which which genes are turned on and how they act and interact. Thus, although their DNA sequences remain unchanged through whar a through what are known as epigenetic inheritance systems, or ElSs for short. It is these systems that provide the second dimension of heredity and evolution (cf Jablonka \& Lamb 2005:113). inheritance $e^{4}$ in most and symbolic inheritance occurs only in humans (cf. Fuentes 2009:13; Jablonka \& Lamb 2005:1-8). According to this view, there is more to heredity than genes, some acquired information is inherited, and evolutionary change can thus result from instruction as well as from selection. This constructivist view moves beyond standard neo-Darwinian approaches and acknowledges that many organisms transmit information via behaviour; thus, acquisition of evolutionary relevant behavioural patterns can occur through socially mediated learning, exactly what Christopher Boehm has also argued recently. Symbolic inheritance, of course, comes with language and the ability to creatively engage in information transfer that can be complex and contain a high density of information. What makes the human species so different and so special, and what makes us human, lies in the way we can organise, transfer and acquire information. It is, therefore, our ability to think and communicate through words and other types of symbols that makes us fundamentally different. According to this view, then, rationality, linguistic ability, artistic ability and religiosity are all facets of symbolic thought and communication (cf. Jablonka \& Lamb 2005:193-231).

According to this view, although it is clear that the symbolic system of acquiring and transmitting information has properties that it shares with other inheritance systems, it is also clearly different from any of them. Jablonka and Lamb thus argue convincingly that human cultural evolution, which is based largely on information transmitted through symbolic communication, has characteristics that make it very different from other types of biological evolution (cf. Jablonka \& Lamb 2005:155f.). Their view of human behaviour and cultural evolution also clearly differs from the classic neo-Darwinian view and the question as to how a cultural entity or behaviour has been selected and who benefits from it. On the contrary, the focus here is as follows: in order to understand why a particular cultural entity exists or changes one has to consider its origin, its reconstruction and its functional preservation. Thus is also implied the question why a new behaviour or idea is generated, how it develops and how it is finally passed on. According to this view, then, cultural evolution can clearly not be explained in purely neoDarwinian terms. To understand how and why cultures change, we need a far richer concept of the environment than is traditionally used in Darwinian theory. It is therefore necessary to recognise that the environment has an interactive role in the generation of cultural traits and entities, as well as their selection and construction (cf. Jablonka \& Lamb 2005:222f.).

According to this view, there clearly is much more to evolution than simply the inheritance of genes. Moreover,

4. Here Jablonka and Lamb argue that the capacity to learn has indeed evolved genetically, but learning itself is now also recognised as an agent of evolutionary
change (cf. Jablonka \& Lamb 2005:155ff.). Therefore, cultural evolution in animals, change (cf. Jablonka \& Lamb 2005:155ff.). Therefore, cultural evolution in animals, different aspects of behaviour (cf. Jablonka \& Lamb 2005:180).

5.This makes clear that the symbolic system, the peculiar, human-specific way of thinking and communicating may have exactly the same basic neural underpinnings as information transmission in other animals, but the nature of the communication (with the self and with others) is not the same (cf. Jablonka \& Lamb 2005:194). 
and importantly, this interactionist perspective blurs any clear prioritisation in inheritance systems and thus requires a clear move away from approaches that are limited to either social or biological focuses. Per this view, 'evolution as construction' is the idea that evolution is never only a matter of biologically developing organisms but of organismenvironment systems interacting and changing over time in a dynamic interactive process of niche construction as a significant evolutionary force alongside natural selection (cf. Fuentes 2009:14; also Ruse 2012:125) ${ }^{6}$. For an understanding of human evolution, this is obviously extremely important: most anthropologists would agree that humans are constructed by, and involved in the construction of, contexts that are simultaneously physiological, behavioural, historical, social and symbolic. In this sense, human behavioural evolution must be seen primarily as a system evolving, rather than a set of independent or moderately connected traits that are evolving (cf. Fuentes 2009:15). Per this view, niche construction is a core factor in human behavioural evolution. The startling conclusion, however, is that we should consider the potential impacts of a diverse array of processes that affect inheritance and evolutionary change, and the possibility that natural selection can occur at multiple levels and may not always be the only, or the main, driver of change (cf. Fuentes 2009:16).

In addition, anthropologists have largely rejected the antiquated dichotomy of nature versus nurture in favour of dynamic, interactive understandings of social, biological and historical complexities. In fact, anthropologists can show that the line dividing the social and the physiological is fairly arbitrary, that no human action or morphological trait exists in a vacuum and that human history is the conjunctural and emergent product of social, physiological, morphological, symbolic and historical interactivities (cf. Fuentes 2010:512). Against this kind of background, it then should come as no surprise that, on the specific matter of human evolution, an anthropologist like Jonathan Marks could argue that instead of seeing ourselves as 'upgraded' versions of our ancestors, we should accept that we have evolved into biocultural ex-apes. In fact, to imagine that we are 'nothing but apes' and to find human nature there, actually constitutes a denial of evolution. As Marks succinctly puts it: we have evolved, get over it! (cf. Marks 2010:513). Evolution is indeed the interactive production of difference and novelty, and we are indeed not our ancestors anymore. What we need is an understanding of evolutionary anthropology that helps us understand what it means to be a cultural, as well as a natural being with remarkable symbolic propensities (cf. Marks 2010:513). ${ }^{7}$

6.In this synergistic interaction between organisms and their environment, niche construction emerges as inherently a constructivist process in which biological, ecological and social/cultural spheres not only interact but also provide a model for human genetic and cultural evolution by incorporating three levels or dimensions: genetic processes, ontogenetic processes and cultural processes (cf. Fuentes 2009:14).

7.Nowadays, of course, scientists assign all extant human beings not just to one species but to one subspecies, Homo sapiens sapiens. All other subspecies have become extinct. The accompanying scientific rhetoric, however, reveals this to be no ordinary subspecies. As Tim Ingold puts it, as 'doubly sapient', the first attribution of wisdom, the outcome of a process of encephalization, marks it out within the of wisdom, the outcome of a process of encephalization, marks it out within the
world of living things. But the second, far from marking a further subdivision, is said to register a decisive break from that world. In what many scientists have called the
Crucial to our ability for symbolic behaviour is our equally remarkable ability for imagination. From a philosophical and theological perspective, it is exactly at this point where the evolution of the moral sense and of morality becomes crucially important. To approach and understand these defining traits, especially the propensity for religious imagination, Fuentes has suggested an important distinction: the quest for understanding the human propensity for religious imagination, and here I would add the quest for understanding the evolution of the moral sense, which can be aided and enriched by investigating more fully the core role of the evolutionary transition between becoming human and being human (Fuentes 2014:1; cf. also Mithen 1996). A distinctively human imagination is, of course, part of the explanation for this evolutionary success. I do believe, however, that in order to begin to understand the emergence of the moral sense and of religion, it would be important to find interdisciplinary points of connection across explanatory frameworks whose focus lies outside the limits of just one specific set of explanations of religion and of any one specific religious tradition (cf. Fuentes 2014; also van Huyssteen 2006) ${ }^{8}$.

In my book Alone in the World: Human Uniqueness in Science and Theology, I argued, from an evolutionary point of view, for the naturalness of religious imagination (cf. van Huyssteen 2006:93ff.). If indeed there is an evolutionary naturalness to religious imagination, or to the propensity of religious belief, then it would be a valid question to ask how such an imagination, as a system emerged over the course of human evolution. Against the background of a broader, more robust view of the many dimensions of evolution that included extensive, interactive niche construction, we can indeed say that Homo sapiens sapiens is a species that had a hand in making itself. From this follows the central theses of evolutionary anthropologist Águstin Fuentes' work: Fuentes first argues that an evolutionary assessment of a distinctively human way of being in the world includes the capacity and capabilities for the possibility of metaphysical thought as a precursor to religion; second, this can be facilitated by recognising the increasingly central role of niche construction ${ }^{9}$, systemic complexity, semiotics and an integration of the cognitive, social and ecological in human communities during the Pleistocene era (roughly two and a half million years to twelve thousand years ago; cf. Fuentes 2014).

Following up on my own quest for understanding the naturalness of the propensity for religious imagination and

\footnotetext{
'human revolution', the earliest representatives of the new subspecies were alleged to have achieved a breakthrough without parallel in the history of life, setting them to have achieved a breakthrough without parallel in the history of life, setting them
on the path of discovery and self-knowledge otherwise known as culture or on the path of discovery and
civilisation (cf. Ingold 2010:514).

8.See also Stosis (2009:315-317), 'The religious system is an exquisite, complex adaptation that serves to support extensive human cooperation and coordination, and social life as we know it'.

9.The concept niche: a niche is the structural and temporal context in which a species exists. As such, it includes space, nutrients and other physical factors as they are experienced, restructured and altered by the organism and also shaped by the presence of competitors, collaborators and other agents in a shared environment (cf. Fuentes 2010). The human socio-cognitive niche is a cognitive and behavioural configuration that is derived relative to the socio-behavioural contexts of previous configuration that is derived relative to the socio-behavioural contexts of previous
hominins. In modern humans, it includes cooperation, egalitarianism, theory of mind (mindreading), cultural transmission and innovation, and language. This is a complex and composite niche unique to the human species and is likely a system whose various components emerged during the Pleistocene to reach its current form (cf. Deacon 1997; Fuentes 2014).
} 
for our aesthetic, creative capacities, Fuentes now believes that this idea can be aided significantly by investigating more fully the core role of the evolutionary transition between becoming human and being human (cf. Fuentes 2014) ${ }^{10}$. This transition itself can be understood better by a broad assessment of hominin ${ }^{11}$ evolution over the last 6 million years. And here the focus should be on the terminal portion of that epoch, meaning the final transition from the archaic form of our genus Homo sapiens into the current form of Homo sapiens sapiens. The focus on this transition, which is a shift to a wholly human way of being in our current socio-cognitive niche, will add to our insight into how we, as humans, experience the world in the here and now. Fuentes now suggests that we can connect this emergence of a distinctly human socio-cognitive and ecological niche to existing in a meaning-laden world, and to the emergence of an imagination that facilitates the capacity and capabilities for the possibility of metaphysical thought. Moreover, this process is intricately connected to our success as a species (Fuentes 2014:2).

While many scholars have proposed, as we will see in my next lecture, that the origin of religion and of religious belief is either an adaptation/exaptation or a by-product of our cognitive complexity, others suggest that it is more complicated than that (cf. Barnard 2012; Boehm 2012; Donald 2001; Sosis 2009; van Huyssteen 2014; Wildman 2009). In addition, Àgustin Fuentes also argues that evolutionary answers to the question of the origin of such systems might not lie in the specific content of religious beliefs, or only in neurological structures themselves, but rather (at least partially) emerge out of the way in which humans successfully negotiated the world during the terminal stages of the Pleistocene (Fuentes 2014:3). Already evolutionary epistemologist Franz Wuketits could argue that metaphysical belief is the result of particular interactions between early humans and their external world and thus results from specific life conditions in prehistorical times (cf. Wuketits 1990:118). More importantly, within this evolutionary context, one can now envision a distinctive imagination as a core part of the human niche that ultimately enabled the possibility of metaphysical thought. It is ultimately this component of our human niche, as our way of being in the world, which is the central aspect of our explanation for why Homo sapiens has flourished while all other hominins, even members of our own genus, have all gone extinct.

According to this view, then, looking at human origins and the archaeology of personhood, and thus at the evolution of our lineage across the Pleistocene, it is evident that there is significant increasing complexity in the way we interface with the world (cf. Fuentes 2014:9): increases in the complexity of culture and social traditions, tool use and manufacture, and trade and the use of fire, as well as enhanced infant survival

10.By 'becoming human', Fuentes refers to aspects of human evolution from the appearance of our genus to the emergence of undisputable Homo sapiens (150 000-200 000 years ago); by 'being human', he refers to evolution in our species since that time (cf. Fuentes 2014).

11.The term 'Hominin' includes humans and all of those genera and species derived from the lineage that split with the chimpanzee lineage (roughly 7 or 8 million years ago). and predator avoidance, increased habitat exploitation and information transfer via material technologies that have increased in intensity rather dramatically in the last 400000 years. All of these increasing complexities are tied directly to a rapidly evolving human cognition and social structure that require increased cooperative capabilities and coordination within human communities. Thinking of this as specific outcomes of a niche construction actually provides a mechanism, as well as a context, for the evolution of this multifaceted response capabilities and coordination within communities (cf. Fuentes 2014:9).

Finally, the emergence of language and a fully developed theory of mind, with high levels of intentionality, empathy, moral awareness, symbolic thought and social unity, would be impossible without an extremely cooperative and mutually integrated social system in combination with enhanced cognitive and communicative capacities as our core adaptive niche. Interestingly, on this point, Fuentes himself wants to incorporate an analysis on compassion (cf. Fuentes 2014:10). I believe this can be pushed even further back by tracing the deep evolutionary roots of empathy and attachment (cf. Hrdy 2009:82ff.; Kirkpatrick 2005; SheetsJohnstone 2008; van Huyssteen 2014). Our genus thus provides a scenario wherein we can envision a distinctively human imagination as a key part of our niche and as a part of the explanation for why our species succeeded and all other hominins went extinct. Fuentes puts it rather forcefully: the imagination and the infusion of meaning into the world by the genus Homo in the late Pleistocene is what underlies, and preceded, our current ability to form a metaphysics which in turn eventually facilitates religious beliefs. This landscape of meaning and associated imagination is also a system that facilitates an array of other symbolic and meaning-laden aspects of human behaviour and experiences that are not at the core of our current niche and lives (cf. Fuentes 2014:11). Important though, there is no single trait that explains human evolutionary success, nor is there a particular environment that created it. And part of this significant toolkit includes a robust imagination and a landscape and perceptual reality wherein everything, whether material or not, is infused with multifaceted meaning.

At the heart of this then is the increasingly rapid and dynamic niche construction by humans, particularly as it relates to aspects of cognitive and symbolic function and social relationships, and the imaginative ability to deploy multiple modes of responding to evolutionary pressures. Fuentes is here in agreement with Terrence Deacon (1997), Donald (2001), King (2007), Alan Barnard (2012) and Robinson (2010) that it is our place as a semiotic species, and the use of symbol as a core infrastructure of our perceptions in our perceptions of, and dealing with the world, that act as a major factor, and thus as a hallmark of human evolution (cf. Fuentes 2014:12).

Humans have an imagination that is part of our perceptual and interactive reality and is a substantive aspect of lived experience. Thus, it is realistic to accept that at some point in the last 400000 years, language and hyper-complex 
intentionality acted to 'lock-in' the more-than-material as our permanent state of being, and so laid the groundwork for the evolution of morality, the possibility of metaphysics, aesthetic propensities, religious imagination and the propensity for religious belief (cf. van Huyssteen 2006) as crucial parts of the uniquely human experience. Now existing in a landscape where the material and social elements have semiotic properties, and where communication and action can potentially be influenced by representations of both past and future behaviour, implies the possession of an imagination, and even something like 'hope', that is, the expectation of future outcomes beyond the predictable (cf. Fuentes 2014:13). The assertion here is, then, that this interactive process occurs as a component of the human niche as it moves dynamically through the Pleistocene as part of the emerging human toolkit.

Imagination, and therefore, religion, per this view is not just an exaptation, a spurious by-product of evolution, but crucial to the process of human evolution and incorporates behavioural processes and a sense of imagination and hope that would, and did, increase the likelihood of innovation and successful responses to evolutionary challenges (cf. Fuentes 2014:14). This also implies that human distinctiveness may have emerged, not merely through the ascent of a hierarchy of semiotic competence, of which symbolic competence was the pinnacle, but, rather, through the entering of what Andrew Robinson refers to as the semiotic matrix (cf. Robinson 2010:150f.). In the Upper-Paleolithic in Europe, and probably earlier in Africa (cf. van Huyssteen 2006:217-270), anatomically modern humans crossed a new cognitive threshold into a semiotic realm, a threshold of semiotic competence that allowed for the combination of remarkable new forms of symbolic communication.

This brief review of human origins and human evolution demonstrates the path and substantive impact of changes in behaviour, life histories and bodies in our human ancestors and us humans ourselves. From this, it is clear that patterns that in the Upper-Paleolithic would lead to the unambiguous appearance of 'art' and 'symbol', now also combined with the evolution of empathy and compassion and the deep caring for others (cf. s Boehm 2012; Fuentes 2014; van Huyssteen 2014). It should therefore not be surprising that a distinctively human imagination is part of the explanation for human evolutionary success and can be seen as one of the structurally significant aspects of the transition from earlier members of the genus Homo to ourselves,

A better understanding of cooperation, empathy, compassion and the use of and engagement with materials, symbols and rituals, and the notion of a semiotic landscape in which humans and our immediate ancestors exist(ed), do indeed move us along in our analysis of what it meant to become human. And the understanding of all of this is indeed a true interdisciplinary process: the insights we gain via the fossil and archaeological record, and behavioural, neurological and physiological systems, provide a more robust understanding of how humans perceive and experience the world. And, it is this process that creates the possibility for an imaginative, potentially metaphysical and eventually religious experiences of the world (cf. Fuentes 2014:17). This should lead to a better understanding of the ubiquitous importance of the propensity for religious imagination, and the reality of religious experiences for Homo sapiens sapiens. This does not imply an argument for any particular adaptive function of religiosity, but rather an argument that in an evolutionary context, neither religion nor religiosity could suddenly have appeared fully blown, and it is therefore valuable to search for the kinds of structures, behaviours and cognitive processes that might facilitate the eventual appearance of such patterns in human beings. If having an imagination is a central part of the human niche, and this imagination is a basal element in the development of metaphysics, one could see how both adaptive and imaginative, creative perspectives could employ that fact as part of their understanding of the human.

For Christian theologians, this provides an exciting bottomup view of the spectacularly complex way in which God has shaped and prepared our species to be physically, mentally and spiritually 'ready' for faith. I believe that my original intuition that there is a naturalness to human imagination, even to religious imagination (cf. van Huyssteen 2006), that facilitates engagement with the world in some ways that are truly distinct from those in other animals - even closely related hominins - thus becomes even more plausible. In Agustin Fuentes' words:

if this is indeed the case, it provides a small, and hopefully fruitful, addition to the toolkit of inquiry for both evolutionary scientists and interdisciplinary theologians interested in reconstructing the long, winding historical path to humanity. (Fuentes 2014:18)

It should be clear now why, as a Christian theologian interested in human origins and the controversial issue of human distinctiveness or 'uniqueness', I have been increasingly drawn to the contributions of scientists and others scholars to the challenging problem of what it means to be human. In my own recent work, I have been deeply involved in trying to construct plausible ways for theology to enter into this important interdisciplinary conversation ${ }^{12}$. An interdisciplinary approach, carefully thought through, can help us identify these shared resources in different modes of knowledge so as to reach beyond the boundaries of our own traditional disciplines in cross-contextual, cross-disciplinary conversation. It can also enable us to identify possible shared conceptual problems as we negotiate the porous boundaries of our different disciplines.

\footnotetext{
12.Against this background, 1 have argued for distinct and important differences between reasoning strategies used by theologians and scientists. I have also, argued, however, that some important shared rational resources may actually be identified for these very different cognitive domains of our mental lives (cf. van Huyssteen 2006). Furthermore, it is precisely these shared rational resources that enable interdisciplinary dialogue and are expressed most clearly by the notion of transversal rationality. In the dialogue between theology and other disciplines, transversal reasoning promotes different, non-hierarchical but equally legitimate ways of viewing specific topics, problems, traditions or disciplines, and creates the ways of viewing specific topics, problems, traditions or disciplines, and creates the kind of space where different voices need not always be in contradiction, or in danger of assimilating one another, but are in fact dynamically interactive with one nother. This notion of transversality thus provides a philosophical window to our wider world of communication through thought and action (cf. Schrag 1992:148ff, Welsch 1996:764f.), and teaches us to construct bridge theories between disciplines, while respecting the disciplinary integrity of reasoning strategies as different as theology and the sciences.
} 
One such shared interdisciplinary problem is exactly the concern for 'what makes us human', for human distinctiveness, for what it means to be a 'self' or a person and how that may, or may not, relate to human origins and the evolution of religious awareness. It is, therefore, precisely in the problem of 'human distinctiveness' that theology and the sciences clearly find a shared, interdisciplinary research trajectory ${ }^{13}$. In the interdisciplinary conversation between theology and the sciences, the boundaries between our disciplines and reasoning strategies are indeed often shifting and porous, and deep theological convictions cannot be easily transferred to philosophy, or to science, to function as 'data' in foreign disciplinary systems. In the same manner, transversal reasoning does not imply that scientific data, paradigms or worldviews can be transported into theology to set the agenda for theological reasoning. This kind of transversal reasoning does mean that theology and science can share concerns and converge on commonly identified conceptual problems such as the problem of human distinctiveness. These mutually critical tasks presuppose, however, the richness of the transversal moment in which theology and anthropology/paleoanthropology may indeed find amazing connections and overlapping intersections on issues of human origins and uniqueness. Furthermore, I believe that the most responsible Christian theological way to look at human nature requires, first of all, a move away from esoteric, abstract notions of human distinctiveness, and second, a return to radically embodied notions of humanness, where our sexuality and embodied moral awareness are tied directly to our embodied self-transcendence as creatures who are predisposed to religious belief. I would further argue that, also from a paleoanthropological point of view, human distinctiveness has emerged as a highly contextualised, embodied notion that is directly tied to the embodied, symbolising minds of our prehistoric ancestors as physically manifested in the spectacularly painted cave walls and portable art of the Upper-Paleolithic. This not only opens up the possibility for converging arguments, from both theology and paleoanthropology, for the presence of imagination and religious awareness in our earliest Cro-Magnon ancestors but also for the plausibility of the larger argument: since the very beginning of the emergence of Homo sapiens, the evolution of those characteristics that made humans uniquely different from even their closest sister species, that is, characteristics like consciousness, language, imagination, moral awareness, symbolic minds and symbolic behaviour have always included religious awareness and religious behaviour.

13. An interesting part of our self-perception is that it is often the less material aspect of the history of our species that fascinates us most in the evolution of modern of the history of our species that fascinates us most in the evolution of modern
humans. We seem to grasp at an intuitive level that issues like language, self-
awareness, imagination, consciousness, moral awareness, symbolic behaviour and mythology are probably the defining elements that really make us human (cf. Lewin 1993:4). Yet, exactly these elements that most suggest humanness are often the least visible in the prehistoric record. For this reason, paleoanthropologist correctly have focused on more indirect but equally plausible material pointers to the presence of the symbolic human mind in early human prehistory. Arguably the most spectacular of the earliest evidences of symbolic behaviour in humans are the paleolithic cave paintings in South West France and in the Basque Country, painted towards the end of the last Ice Age. The haunting beauty of these painted towards the end of the last Ice Age. The haunting beauty of these prehistoric images, and the creative cultural explosion that they represent, should indeed fascinate any theologian interested in human origins. Moreover, I believe that the European Upper-Paleolithic era represents quite a spectacular fina transition from the archaic form of our genus Homo sapiens into the current form homo sapiens sapiens. The focus on this transition, which is a shift to a wholly human way of being in our current socio-cognitive niche, will add to our insigh into how we, as humans, experience the world in the here and now.
Paleoanthropologist Ian Tattersall has argued exactly this point: because every human society, at one stage or another possessed religion of some sort, complete with origin myths that purportedly explain the relationship of humans to the world around them, religion cannot be discounted from any discussion of typically human behaviours (1998:201). There is indeed a naturalness to religious imagination that challenges any viewpoint that would want to see religion or religious imagination as an arbitrary or esoteric faculty of the human mind. What has emerged from the work of scientists like Steven Mithen, William Noble, Iain Davidson, Merlin Donald, Ian Tattersall and Terrence Deacon, and should be of primary interest to theologians working on evolutionary anthropology, is that human mental life includes biologically unprecedented ways of experiencing and understanding the world, from aesthetic experiences to spiritual contemplation, which is exactly the point now being made by Águstin Fuentes about niche construction. Also, Terrence Deacon has made the important point that the spectacular UpperPaleolithic imagery and the burial of the dead, though not final guarantees of shamanistic or religious activities, do suggest strongly the existence of sophisticated symbolic reasoning, of imagination and a religious disposition of the human mind (cf. Deacon 2003:504ff.). The symbolic nature of Homo sapiens also explains why mystical or religious inclinations can even be regarded as an essentially universal attribute of human culture (cf. Deacon 1997:436), and opens up an interesting space for Jean Clottes and David LewisWilliam's argument for a shamanistic interpretation of some of the most famous of the paleolithic imagery (cf. Clottes \& Lewis-Williams 1998; Lewis-Williams 2002). There is in fact no culture that lacks a rich mythical, mystical and religious tradition. The co-evolution of language and brain not only implies, however, that human brains could have been reorganised in response to language and the environment in a dynamic process of niche construction but also alerts us to the fact that the consequences of this unprecedented evolutionary transition from becoming human to being human must be understood on many levels as well.

The idea that religious imagination might not be an isolated faculty of human rationality, and that mystical or religious inclinations can indeed be regarded as an essentially universal attribute of the human mind, has recently also been taken up in interdisciplinary discussion by some theologians (cf. Shantz 2009). Shantz has offered a fascinating and entirely plausible account of religious experience, and of religious ecstasy, as not only a significant feature of the apostle Paul's life, but beyond that, as part of a strong argument for the epistemological relevance of religious experience. Her argument for the universal significance of religious experience, also alternate states of consciousness, is first of all an argument against a completely disembodied exegesis that is restricted, and epistemically limited, to the analysis and comparison of biblical texts. It is also, however, an argument for forms of cognition that go beyond linguistic dominance: the human self and its embodied experience includes elements that are known apart from language, elements that are still essentially human (cf. Shantz 2009:9f.). In this exciting interdisciplinary 
project, her discussion partners in the end are cognitive neuroscientists, textual exegetes and social anthropologists, and the point is not to argue that God is generated by the brain, but rather that God cannot be known apart from the brain, the embodied person (cf. Shantz 2009:15).

Also, theologian Niels Henrik Gregersen has argued that imagination, and therefore also religious imagination, is not an isolated faculty of human rationality, but can be found at the very heart of human rationality. According to this view, then, the same 'naturalness' of imagination also applies to religious imagination, and religious imagination should not be seen as something extra or esoteric that can be added, or subtracted, from other mental states (cf. Gregersen 2003:1f., 23). More importantly, though, a theory about the emergence of religious imagination and of religious concepts, of course, does not at all answer the philosophical question about the validity of religion, or the even more complex theological question whether, and in what form, religious imagination might refer to some form of reality or not, or might be true or not. As an interdisciplinary problem, however, the reasons that may undergird the unreasonable effectiveness of religious belief and thought may transcend the scope of any one discipline when it comes to evaluating the integrity of religious belief. In this specific conversation, we can reach an interdisciplinary agreement that religious imagination and religious concepts should be treated equally with all other sorts of human reflection. Religious imagination should, therefore, be treated as an integral part of human cognition, not separable from our other cognitive endeavours. Clearly early human behaviour is not understood if we do not take this religious dimension into account.

I suggest that a theological appropriation of these rich and complex results of science at the very least should inspire the theologian carefully to trace and rethink the complex evolution of the notion of human distinctiveness, or the imago $D e i$, in theology. Interpretations of the doctrine of the imago Dei have indeed varied dramatically throughout the long history of Christianity (cf. van Huyssteen 2006:111-162). Theologians are now challenged to rethink what human uniqueness might mean for the human person, a being that has emerged biologically as a centre of self-awareness, identity and moral responsibility. Personhood, when reconceived in terms of embodied imagination, symbolic propensities and cognitive fluidity, may enable theology to revision its notion of the imago Dei as an idea that does not imply superiority or a greater moral value for humans over animals or earlier hominids, but which might express a specific task and purpose to set forth the presence of God in this world (cf. Hefner 1998:88). In theology I would, therefore, call for a revisioning of the notion of the imago Dei in ways that would not be disembodied or overly abstract, but that instead acknowledges our embodied existence, our close ties to the animal world and its uniqueness, and to those hominid ancestors that came before us, while at the same time focusing on what our symbolic and cognitively fluid minds might tell us about the emergence of an embodied human distinctiveness, consciousness and personhood, and the propensity for religious awareness and experience.

In my own recent work, I have argued that theologians should be intensely aware of how interpretations of the imago Dei have indeed varied dramatically throughout the long history of Christianity (cf. van Huyssteen 2006). As interdisciplinary theologians, we are now challenged to rethink what human distinctiveness might mean for the human person, a being that has emerged biologically as a centre of embodied selfawareness, identity and moral responsibility. This notion of self or personhood, when reconceived in terms of embodied imagination, symbolic propensities and cognitive fluidity, will now enable theology to revision its own notion of the imago Dei as emerging from nature itself, an idea that does not imply any superiority or a greater moral value over other animals or earlier hominins. In this kind of interdisciplinary conversation, theology can actually help to significantly broaden the scope of what is meant by 'human distinctiveness,' or rather, the notion of self or personhood. However, Homo sapiens is not only distinguished by its remarkable embodied brain, but also by a stunning mental cognitive fluidity expressed in imagination, creativity, linguistic abilities and symbolic propensities. As real-life, embodied persons of flesh and blood, we humans are also affected by hostility, arrogance, ruthlessness and cunning, and therefore are inescapably caught between what we have come to call 'good and evil'. This experience of good and evil, and theological distinctions between evil, moral failure, sin, tragedy and redemption lie beyond the empirical scope of the fossil record, and therefore beyond the scope of science (cf. van Huyssteen 2006:325). It certainly is our evolutionarily developed bodies that are the bearers of human distinctiveness, and it is precisely this embodied existence that confronts us with the realities of vulnerability, sin, tragedy and affliction. Here, then, theology has a special task: in terms of the complexity of the history of human niche construction, theology may now not only provide a rather unique key to understanding the profound tragic dimensions of human existence but also as to why religious belief has provided our distant ancestors, and us, with dimensions of hope, redemption and grace.

Rethinking theologically the imago Dei as emerging from nature opens up theology to the interdisciplinary impact of the fact that the potential arose in the embodied human mind to undertake science and technology, to create art and to discover the need and ability for religious belief. It is in this sense that we cannot understand early human behaviour, or human personhood itself, if we do not take the evolution of this fundamental religious dimension into account.

\section{Acknowledgements Competing interests}

The author declares that he has no financial or personal relationships which may have inappropriately influenced him in writing this article. 


\section{References}

Barnard, A., 2012, Genesis of symbolic thought, Cambridge University Press, Cambridge. Boehm, C., 2012, Moral origins. The evolution of virtue, altruism and shame, Basic Books, New York, NY.

Cartmill, M. \& Brown, K., 2012, 'Being human means that "Being Human" means whatever we say it means', Evolutionary Anthropology 21 (5), 183-184.

Clottes, J. \& Lewis-Williams, D., 1998, The shamans of prehistory: Trance and magic in the painted caves, Harry N. Abrahams, New York.

Deacon, T., 1997, The symbolic species: The co-Evolution of language and the brain, Norton, New York.

Deacon, T., 2003, 'Language', in J. Wentzel Vrede van Huyssteen (eds.), Encyclopedia of science and religion, vol. 2. pp. 504-505, Macmillan, New York.

De Waal, F., 2006, Primates and philosophers: How morality evolved, Princeton University Press, Princeton.

De Waal, F., 2013, The Bonobo and the Atheist, W. W. Norton \& Co, New York.

Donald, M., 2001, A mind so rare: The evolution of human consciousness, Norton, New York.

Fowler, C., 2004, The archeology of personhood: An anthropological approach, Routledge, London.

Fuentes, A., 2009, 'A new synthesis: Resituating approaches to the evolution of human behavior', Anthropology Today 25(3), 12-17. https://doi.org/10.1111/j.1467-8322. 2009.00667.x

Fuentes, A., 2010, “"On nature and the human: Introduction," and "More than human nature"', American Anthropologist 112(4), 512-521. https://doi.org/ 10.1111/j.1548-1433.2010.01271.x

Fuentes, A., 2014. 'Human evolution, niche complexity, and the emergence of a distinctly human imagination', Time and Mind 7(3), 241-257.

Gregersen, N.H., 2003, 'The naturalness of religious imagination and the idea of revelation', Ars Disputandi: The Online Journal for Philosophy of Religion 3, viewed 20 January 2017, from www.arsdisputandi.org

Hefner, P., 1998, 'Biocultural evolution and the created co-Creator', in T. Peters (ed.), Science and theology: The new consonance, pp.174-188, Westview Press, Boulder, CO.

Hrdy, S., 2009, Mothers and others: The evolutionary origins of mutual understanding, Harvard University Press, Cambridge, MA.

Ingold, T., 2010, 'What is a human being?', American Anthropologist 112(4), $512 \mathrm{f}$

Jablonka, E. \& Lamb, M., 2005, Evolution in four dimensions: Genetic, epigenetic behavioral, and symbolic variation in the history of life, MIT Press, Cambridge, MA.

Kearney, R., 2004, On Paul Ricoeur: The owl of minerva, Ashgate, Aldershot.

King, B., 2007, Evolving God: A provocative view on the origins of religion, Doubleday, New York.

Kirkpatrick, L.A., 2005, Attachment, evolution, and the psychology of religion, The Guilford Press, New York.

Lewin, R., 1993, The origins of modern humans, Scientific American Library, New York. Lewis-Williams, D., 2002, The mind in the cave: Consciousness and the origins of art, Thames and Hudson, New York.

Marks, J., 2010, 'Off human nature', American Anthropologist 112(4), 512.

Mellars, P., 1989, 'Major issues in the emergence of modern humans', Current Anthropology 30(3), 349-385. https://doi.org/10.1086/203755

Mellars, P., 1991, 'Cognitive changes and the emergence of modern humans in Europe', Cambridge Archeological Journal 1(1), 63-76.

Mithen, S., 1996, The prehistory of the mind: A search for the origins of art, religion, and science, Thames and Hudson, London.

Mithen, S., 2006, The singing Neanderthals: The origins of music, language, mind, and body, Harvard University Press, Cambridge, MA.
Noble, W. \& Davidson, I., 1996, Human evolution, language and mind: A psychological and archeological inquiry, Cambridge University Press, Cambridge.

Potts, R., 1996, Humanity's descent, Morrow, New York.

Potts, R., 2012. 'Environmental and behavioral evidence pertaining to the evolution of early Homo', Current Anthropology 53(Suppl 6), S299-S317. https://doi.org/ 10.1086/667704

Robinson, A., 2010, God and the world of signs: Trinity, evolution, and the metaphysical semiotics of C.S. Pierce, Brill Publishers, Leiden.

Ruse, M., 2012, The philosophy of human evolution, Cambridge University Press, Cambridge.

Schrag, C., 1992, The resources of rationality: A response to the postmodern challenge, Indiana University Press, Bloomington, IN.

Shantz, C., 2009, Paul in ecstasy: The neurobiology of the Apostle's life and thought, Cambridge University Press, Cambridge.

Sheets-Johnstone, M., 1990, The roots of thinking, Temple University Press, Philadelphia. PA.

Sheets-Johnstone, M., 2008, The roots of morality, The Pennsylvania State Press, University Park, PA.

Stosis, R., 2009, 'The Adaptationist-Byproduct debate on the evolution of religion: Five misunderstandings of the adaptationist program', Journal of Cognition and Five misunderstandings of the adaptationist program', Journal of Cognition
Culture 9, 315-332. https://doi.org/10.1163/156770909X12518536414411

Tattersall, I., 1998, Becoming human: Evolution and human uniqueness, Hartcourt Brace, New York.

Tattersall, I., 2002, The monkey in the mirror: Essays on the science of what makes us human, Hartcourt, New York.

Tattersall, I. \& Mowbray, K., 2003, 'Human evolution', in J. Wentzel Vrede van Huyssteen (ed.), Encyclopedia of science and religion, vol. 1,pp. 298-301, Macmillen, New York.

Van Huyssteen, J.W., 2006, Alone in the world: Human uniqueness in science and theology, Wm. B. Eerdmans, Grand Rapids, MI.

Van Huyssteen, J.W., 2009, 'Interdisciplinary perspectives on human origins and religious awareness', in C. Renfrew \& I. Morley (eds.), Becoming human: religious awareness, in C. Renfrew \& I. Morley (eds.), Becoming human:
Innovation in prehistoric material and spiritual culture, pp. 235-253, Cambridge Innovation in prehistoric materic
University Press, Cambridge.

Van Huyssteen, J.W., 2010a, 'What makes us human? The interdisciplinary challenge to theological anthropology and Christology', Toronto Journal of Theology 26(2), 143-160. https://doi.org/10.3138/tjt.26.2.143

Van Huyssteen, J.W., 2010b, 'When were we persons? Why hominid evolution holds the key to embodied personhood', Neue Zeitschrift for Systematische Theologie 52, 329-349. https://doi.org/10.1515/nzst.2010.021

Van Huyssteen, J.W., 2010c, 'Coding the nonvisible: Epistemic limitations and understanding symbolic behavior at Çatalhöyük', in I. Hodder (ed.), Religion in the emergence of civilization: Çatalhöyük as a case study, pp. 99-121, Cambridge University Press, Cambridge.

Van Huyssteen, J.W., 2011, 'Post-Foundationalism and human uniqueness: A reply to responses', Toronto Journal of Theology 27(1), 73-86. https://doi.org/10.3138/ tjt.27.1.73

Van Huyssteen, J.W., 2013, 'The historical self: Memory and religion at Çatalhöyük', in I. Hodder (ed.), Vital matters: Religion and change at Çatalhöyük, Cambridge University Press, Cambridge.

Van Huyssteen, J.W., 2014, 'From empathy to embodied faith: Interdisciplinary perspectives on the evolution of religion', in F. Watts \& L. Turner (eds.), Evolution, religion, and cognitive science: Critical and constructive essays, pp. 132-152, Oxford University Press, Oxford.

Welsch, W., 1996, Vernunft: Die Zeitgenössische Vernunftkritik und das Konzept der Transversalen Vernunft, Suhrkamp Taschenbuch, Frankfurt am Main.

Wildman, W., 2009, Science and religious anthropology, Ashgate Press, Farnham.

Wuketits, F.M., 1990, Evolutionary epistemology and its implications for humankind, SUNY Press, Albany, NY 